\title{
Qualidade e reúso da água de caldeira
}

O objetivo desse trabalho foi avaliar a qualidade de água proveniente de caldeira e propor formas de reúso das águas provenientes de processos de purga, descarga das válvulas de segurança e descarga de fundo das caldeiras. Propôs-se o reúso da água descarga de purga e descarga das válvulas de segurança das caldeiras para retorno no processo produtivo e dimensionamento de reservatório para descarga de fundo objetivando irrigação dos telhados da indústria. Para verificação da qualidade da água de uma caldeira fogotubular, válvulas de segurança e purga, foram realizadas análises de temperatura, alcalinidade total, alcalinidade bicarbonato, alcalinidade carbonato, alcalinidade hidróxido, condutividade elétrica, sólidos totais dissolvidos, dureza total, cloretos, ferro total, cloro residual e pH. Foram realizadas três análises de temperatura com termômetro de bulbo seco em triplicata no período de maior insolação do dia, com o sistema em uso e em desuso, a fim de verificar a eficiência de irrigação no telhado após reúso. Quanto ao reúso proposto, o processo se mostrou satisfatório complementando a base de sustentabilidade, com reutilização dessa água na própria caldeira com temperatura de aproximadamente 70 a $80^{\circ} \mathrm{C}$. Observou-se redução de custos devido ao menor consumo de água, uma vez que anteriormente era utilizada água da concessionária à temperatura ambiente e, menor gasto energético para aquecimento da água para vaporização, ou seja, menor utilização de matéria-prima de lenha (redução de $3,5 \mathrm{~m}^{3}$ de lenha para $2 \mathrm{~m}^{3}$ ). A média de gasto com água mensal seria de $87 \mathrm{~m}^{3} \times 3,7088=\mathrm{R} \$ 320,684-30 \%=R \$ 96,21$ de economia por reaproveitar a água da descarga de fundo e das válvulas de segurança. A média de gasto da lenha por dia era $3,5 \mathrm{~m}^{3}-2,0 \mathrm{~m}^{3}$, passou a economizar 1,5 por dia após reaproveitar a água da descarga de fundo e das válvulas de segurança, $1,5 \mathrm{~m}^{3} \times 30$ dias $=45 \mathrm{~m}^{3} \times \mathrm{R} \$ 55,00=\mathrm{R} \$ 2.475,00$ de economia por mês. Com relação às variáveis de válvula de segurança e purgadores, foi possível constatar que $\mathrm{pH}$ e alcalinidade total se encontram fora dos limites estabelecidos pelas especificações técnicas. Concluiu-se que a água de descarga de purga e das válvulas de segurança de caldeiras que atinjam aproximadamente $70^{\circ} \mathrm{C}$ a $80^{\circ} \mathrm{C}$ pode ser reutilizada na própria caldeira com consequente economia de lenha e água, devendo-se, entretanto, proceder a um tratamento com adição de cal e/ou soda cáustica, conforme análise da USI.

Palavras-chave: Água; Industria; Reúso.

\section{Boiler water quality and reuse}

The objective of this work was to evaluate the quality of water coming from the boiler and to propose ways of reusing water from purging processes, discharge of safety valves and bottom discharge of boilers. It was proposed to reuse the purge discharge water and the boiler safety valves to return to the production process and to design a reservoir for the bottom discharge to irrigate the roofs of the industry. To check the water quality of a fogotubular boiler, safety valves and purge, analyzes of the following variables were performed: temperature, total alkalinity, bicarbonate alkalinity, carbonate alkalinity, hydroxide alkalinity, electrical conductivity, total dissolved solids, total hardness, chlorides, total iron, residual chlorine and pH. Three temperature analyzes were carried out with a dry bulb thermometer in triplicate in the period of the greatest insolation of the day, with the system in use and in disuse, in order to verify the irrigation efficiency on the roof after reuse. As for the proposed reuse, the process proved to be satisfactory, complementing the sustainability base, with the reuse of this water in the boile itself with a temperature of approximately 70 to $80^{\circ} \mathrm{C}$. It was observed a cost reduction due to lower water consumption, since previously water from the concessionaire was used at room temperature and less energy expenditure for heating water for vaporization, that is, less use of raw wood material (reduction of $3.5 \mathrm{~m}^{3}$ of firewood to $2 \mathrm{~m}^{3}$ ). The average monthly water expenditure a $3.5 \mathrm{~m}^{3}-2.0 \mathrm{~m}^{3}, \mathrm{stated}$ to 5 ave $1.5 \mathrm{per}$ day after reusing th Regarding the variables of the safety valve and traps, $\mathrm{pH}$ and total alkalinity are outside the limits established by the technical specifications. It was concluded that the purge discharge wate and the boiler safety valves that reach approximately 70 to $80^{\circ} \mathrm{C}$ can be reused in the boiler itself with consequent saving of firewood and water, however, it is necessary to proceed to a treatment with the addition of lime and/or caustic soda, according to USI analysis.

Keywords: Water; Industry; Reuse.

Topic: Desenvolvimento, Sustentabilidade e Meio Ambiente

Reviewed anonymously in the process of blind peer.

Pacelli Dias de Rezende (D)

Universidade Vale do Rio Verde de Três Corações, Brasil

http://lattes.cnpq.br/5877619283929411

http://orcid.org/0000-0002-7241-1269

pacelli.dias@bol.com.br

Ramiro Machado Rezende (iD)

Universidade Vale do Rio Verde de Três Corações, Brasil

http://lattes.cnpq.br/0137435812541824

http://orcid.org/0000-0003-4019-5837

prof.ramiro.rezende@unincor.edu.br

Rosângela Francisca de Paula Vitor Marques (D) Universidade Vale do Rio Verde de Três Corações, Brasil

http://lattes.cnpq.br/6991929220004023

http://orcid.org/0000-0001-6646-0809

rosangela.marques@unincor.edu.br
Renata Alves Lara Silva Rezende (iD)

Universidade Vale do Rio Verde de Três Corações,

Brasil

http://lattes.cnpq.br/3793171217216141

http://orcid.org/0000-0001-6410-9716

renata vga@yahoo.com.br

Alisson Souza de Oliveira (iD

Universidade Vale do Rio Verde de Três Corações,

Brasil

http://lattes.cnpq.br/6716188774645620

http://orcid.org/0000-0001-7885-9542

prof.alisson.oliveira@unincor.edu.br

Claudiomir da Silva dos Santos (iD)

Instituto Federal Sul de Minas Gerais, Brasil

http://lattes.cnpq.br/7460335760795185

http://orcid.org/0000-0002-0007-7273

claudiomir.santos@muz.ifsuldeminas.edu.br

\section{Camilo Nunes Pereira}

Universidade Vale do Rio Verde de Três Corações, Brasil

http://lattes.cnpq.br/2098205849619454 http://orcid.org/0000-0003-0580-7631 camilonp@yahoo.com.br

\section{Referencing this:}

REZENDE, P. D.; REZENDE, R. M.; MARQUES, R. F. P. V.; REZENDE, R. A. L. S.; OLIVEIRA, A. S.; SANTOS, C. S.; PEREIRA, C. N.. Qualidade e reúso da água de caldeira. Revista Ibero Americana de Ciências Ambientais, v.12, n.6, p.566-575, 2021. DOI: http://doi.org/10.6008/CBPC2179$\underline{6858.2021 .006 .0047}$

DOI: $10.6008 / C B P C 2179-6858.2021 .006 .0047$ 


\section{INTRODUÇÃO}

O planeta terra vem sofrendo grandes impactos ambientais e a geração de resíduos nos processos industriais tem se tornado um problema recorrente. Segundo o Balanço Energético Nacional apresentado pelo Ministério de Minas e Energia (BRASIL, 2015), no ano de 2014 houve um aumento de produção de energia que atingiu o montante de 590,5 TWh. De acordo com o relatório citado, a maior fonte de energia produzida no país é proveniente das hidroelétricas $(70,6 \%)$ seguido pelas indústrias de gás natural $(11,3 \%)$ e pela energia produzida por meio de biomassa $(7,6 \%)$.

O consumo de energia industrial vem aumentando na medida em que as indústrias se tornam maiores e a demanda de produtos cresce. Esse processo interfere diretamente no meio ambiente por meio da extração de matéria prima (água) e pelo descarte final desse resíduo gerado pelas caldeiras. As caldeiras são empregadas em processos industriais, na alimentação de máquinas térmicas, autoclaves para esterilização de materiais diversos, cozimento de alimentos pelo vapor, calefação ambiental, entre outras. Portanto qualquer problema que elas apresentem não significa apenas uma parada para a manutenção, mas uma paralisação na produção e grande risco à segurança. Conforme Rothbarth (2010), atualmente, cerca de $40 \%$ da energia elétrica produzida no mundo é obtida por intermédio da geração de vapor a partir do carvão mineral. Se considerarmos as fontes de energia disponíveis, é possível afirmar que a matriz energética brasileira se baseia fundamentalmente nas fontes renováveis, uma vez que correspondem a $78,2 \%$ da oferta interna de energia.

No Brasil, a NR-13 estabeleceu medidas de segurança para usuários destes sistemas (caldeiras ou vasos de pressão) (BRASIL, 1978). Alguns minerais como cálcio e magnésio influenciam na dureza da água na incrustação das tubulações, gerando danos em equipamentos e utensílios além de afetarem a ação dos detergentes na limpeza, aumentando consequentemente o custo da produção. O controle de qualidade da água de reúso da caldeira deve ocorrer regularmente, de modo a garantir a redução de efeitos indesejáveis nas instalações da organização, como corrosão e incrustações de partículas sedimentares, que conferem riscos de contaminação além de exporem a saúde do consumidor. Todos os reparos ou alterações em caldeiras devem respeitar o projeto de construção e prescrições do fabricante quanto aos materiais, procedimentos de execução, de controle de qualidade, qualificação e certificação de pessoal. Os projetos de alteração ou reparo devem ser concebidos previamente sempre que as condições de projeto forem modificadas e sempre que forem realizados reparos que possam comprometer a segurança. Todas as intervenções que exijam mandrilhamento ou soldagem em partes que operem sob pressão devem ser seguidas de teste hidrostático, com características definidas pelo profissional habilitado.

Muitas vezes as águas de caldeira são descartadas diretamente no próprio pátio da empresa, em esgotos e riachos, com uma temperatura em torno de $70^{\circ} \mathrm{C}$ a $80^{\circ} \mathrm{C}$. As águas de descarga de fundo na maioria das vezes são descartadas com características inapropriadas para o meio ambiente, apresentando oscilações em parâmetros como $\mathrm{pH}$, alcalinidade, dureza total, sílica, ferro total, índice de sólidos totais dissolvidos, cloretos e condutividade, causando alteração na biodiversidade aquática. 
Diante do exposto, o objetivo deste trabalho foi avaliar a qualidade de água proveniente de caldeira e propor formas de reaproveitamento das águas provenientes de processos de purga, descarga das válvulas de segurança e descarga de fundo das caldeiras.

\section{MATERIAIS E MÉTODOS}

\section{Caracterização da área}

O ensaio foi conduzido em uma empresa do ramo de vestuário no município de Paraguaçu - MG (Maia \& Maia) que confecciona roupas sociais masculinas e que emprega atualmente cerca de 150 funcionários. No processo de produção são utilizadas máquinas europeias e japonesas, o que proporciona exatidão e precisão nos cortes e agilidade na produção. O sistema de produção por ser informatizado implica em aumento de produtividade com benefícios também ao meio ambiente, evitando retrabalho e desperdício.

\section{Descrição dos processos produtivos}

Os processos produtivos são todos controlados por células, iniciando pelo corte, onde é feito o infesto do tecido. Em seguida, o tecido é cortado e etiquetado e é colada uma entretela nas partes necessárias. Assim as peças são separadas em caixas e prontas para entrar na produção. A produção de paletós é constituída por células para preparação das mangas, costas e golas, frentes do paletó, montagem, acabamento, passadoria e expedição. Cada processo ocorre em sua célula. Da mesma forma, no setor das calças tem-se células de preparação de cós e passante, montagem, passadoria e expedição, que é o local que a calça é casada com o paletó.

Todas as células possuem vários times e em cada célula existe um trilho, onde por meio de caixas, os produtos fluem para próxima etapa de acordo com as operações executadas nas peças. Todas as células da empresa são em formato de linha reta. No final de cada célula existe o processo de revisão das peças produzidas, além do cálculo da eficiência e meta do dia, ou seja, a produção de 560 peças/dia.

\section{Funcionamento da caldeira}

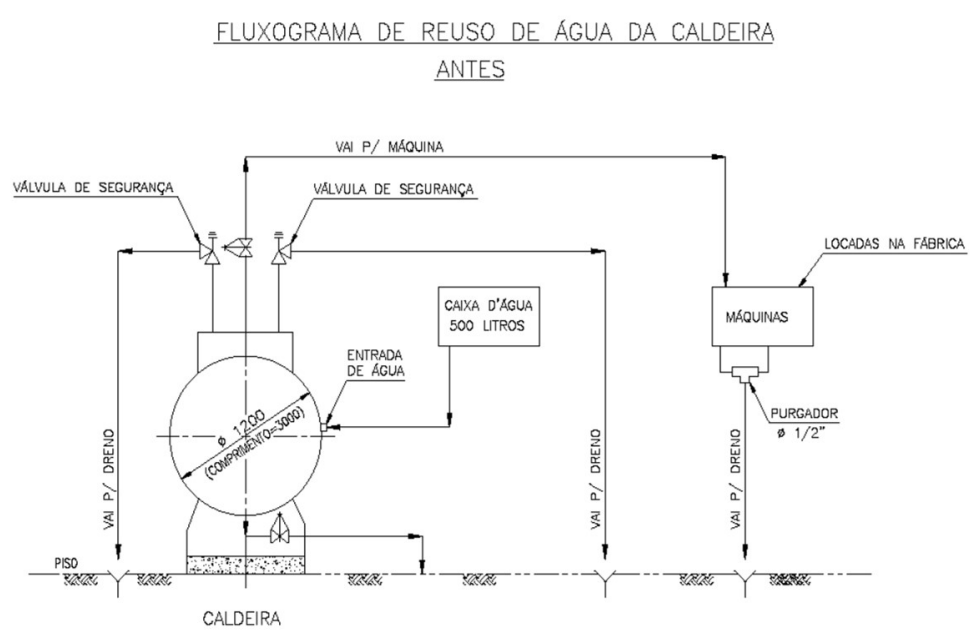

Figura 1: Fluxograma de reúso de água de caldeira fogotubular utilizado no processo de uma empresa do ramo de vestuário no município de Paraguaçu-MG. 


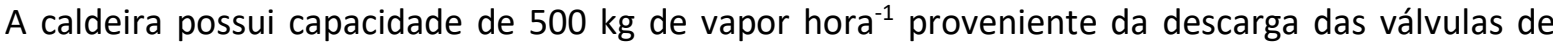
segurança e da purga utilizadas no processo de fabricação têxtil. A água que sai dos purgadores e das válvulas de segurança funciona da seguinte forma: quando o vapor vai para as tubulações e perde calorias tem-se o condensado que é purgado pelos purgadores e muitas das vezes é descartado no meio ambiente (Figura 1).

\section{Proposta de reúso da água de caldeira: descarga de fundo, purgadores e válvulas de segurança}

Foi proposto o reúso da água descarga de purga e descarga das válvulas de segurança das caldeiras para o retorno no processo produtivo. Realizou-se ainda o dimensionamento de um reservatório para a descarga de fundo objetivando a irrigação dos telhados da indústria visando à economia de água e conforto térmico. Para nortear este trabalho foi realizado a análise e coleta de dados da literatura, e o estudo teórico aplicado nas caldeiras a combustível de lenha por meio da avaliação de um cenário comum nas indústrias. No estudo de caso, endossado nos diversos catálogos de fabricantes disponíveis, foi selecionada uma caldeira fogotubular, nos moldes do modelo exposto na Figura 1.

\section{Variáveis de qualidade da água de caldeira e métodos}

Na Tabela 1 são mostradas as informações técnicas referentes às variáveis de qualidade da água de caldeira e os métodos utilizados.

Para a verificação da qualidade da água de uma caldeira fogotubular (descarga de fundo), válvulas de segurança e purga, foram realizadas análises das seguintes variáveis: temperatura, alcalinidade total, alcalinidade bicarbonato, alcalinidade carbonato, alcalinidade hidróxido, condutividade elétrica, sólidos totais dissolvidos, dureza total, cloretos, ferro total, cloro residual e $\mathrm{pH}$, conforme metodologia do Standard of Methods (APHA et al., 2005).

O período de monitoramento foi de fevereiro de 2017 a julho de 2019, totalizando 13 coletas para as análises de água da caldeira fogotubular, usando os critérios da norma NBR9898-ABNT. Foi realizada uma única vez e coletados cinco (5) litros da amostra, a qual o laboratório Aqualic recomendou de acordo coma norma supracitada.

Tabela 1: Variáveis e métodos utilizados para verificação da qualidade da água.

\begin{tabular}{ll}
\hline Normas & NR-17 Ergonomia - REFERÊNCIA \\
& NHO 06 (Avaliação da Exposição Ocupacional ao Calor) -REFERÊNCIA \\
\hline Equipamentos & Monitor Eletrônico de Stress Térmico POLITESTE Modelo TGM 100 \\
& № de Série: 510727820 \\
\hline Aplicação & Conjunto Convencional Eletrônico para Determinação do IBUTG \\
\hline Composição do aparelho & Termômetro de Globo (tg) \\
& Termômetro de Bulbo Úmido Natural (tbn) \\
& Termômetro Bulbo Seco (tbs) \\
\hline
\end{tabular}

Para as análises de água das válvulas de segurança, purga e água de refrigeração do telhado, foi realizada uma coleta que se deu no dia 11/09/2019, essa coleta foi solicitada pelo laboratório Aqualic. As variações da qualidade água de caldeira fogotubalar ocorrerá caso a caldeira para de funcionar. (Figura 6). Os procedimentos de coleta e preservação seguiram ao Standard of Methods (APHA et al., 2005).

As amostras de águas da caldeira foram coletadas e levadas ao Laboratório USI Industrial Ltda. em 
Contagem - MG. As demais amostras de água foram analisadas pela Laboratório Aqualic em Varginha - MG.

O conforto térmico foi avaliado por meio de três análises de temperatura com um termômetro de bulbo seco (temperatura do ar) em triplicata no período de maior insolação do dia (12hs às $15 \mathrm{hs}$ ), seguindo de altura de acordo com o termômetro globo de bulbo seco, conforme a norma NR17, patrão de conforto térmico. Com o sistema em uso e com o sistema em desuso, a fim de verificar a eficiência de irrigação no telhado (Figura 7), conforme NR 17. O laudo de calor foi realizado pela empresa Vitall Consultoria, as normas utilizadas foram NHO06 e NR17. A metodologia foi realizada sem o uso da umidificação do telhado, para efeito de comparação das medições foram realizadas duas (2) medições no mesmo ponto central da fábrica, em horários iguais para se ter efeito comparativo real (atendendo as mesmo as condições climáticas com uma medição com o telhado seco e outra úmida).

\section{Tratamento dos dados}

Para verificação do desempenho da caldeira das análises de descarga de fundo, válvulas de segurança, purga, comparou-se os dados obtidos com os limites estabelecidos conforme padrões de Trovati (2014) (Tabela 2).

Tabela 2: Especificações da Marchand Chimie para os parâmetros de água de caldeira.

\begin{tabular}{ll}
\hline Variáveis & Valores padrões \\
\hline $\mathrm{pH}$ & 11,0 a 12,0 \\
Alcalinidade & 150 a $600 \mathrm{mg} \cdot \mathrm{L}^{-1} \mathrm{CaCO}_{3}$ \\
Dureza & $<50,0 \mathrm{mg} \cdot \mathrm{L}^{-1} \mathrm{CaCO}_{3}$ \\
Ferro Total & $<5,0 \mathrm{mg} \cdot \mathrm{L}^{-1} \mathrm{Fe}$ \\
Índice TDS & $<1500 \mathrm{mg} \cdot \mathrm{L}^{-1}\left({ }^{*}\right)$ \\
Cloretos & $<150 \mathrm{mg} \cdot \mathrm{L}^{-1}\left({ }^{*}\right)$ \\
Condutividade & $<3000 . \mathrm{S}^{-1}, 25^{\circ} \mathrm{C}\left({ }^{*}\right)$ \\
\hline
\end{tabular}

Fonte: Trovati (2014).

Para análise de água do telhado, além dos limites recomendados pela Marchand Chimie, utilizou-se os padrões para Classe 1 - Lavagem de carros e outros usos que requerem o contato direto do uso da água, com possível aspiração de aerossóis pelo operador incluindo chafarizes conforme a Norma ABNT - NBR 13.969/97.

\section{RESULTADOS E DISCUSSÃO}

A água de descarga de fundo foi utilizada no reúso para refrigeração do ambiente. Para isso, foi proposto um modelo em que a água de descarga é descartada em um tanque de refrigeração de $1000 \mathrm{~L}$, observou-se a quantidade de agua descarregada da descarga do fundo da caldeira fogotubular, verificando -se que o tanque de 1000 L era o suficiente para reúso no telhado. Posteriormente reutilizada em um circuito fechado, bombeada para o telhado e expelida por aspersores que, consequentemente, refrigeram o telhado visando conforto térmico dentro da empresa para os funcionários (Figura 2).

Quanto ao reúso proposto da água de descarga de purga e descarga das válvulas de segurança das caldeiras, o processo se mostrou satisfatório complementando a base de sustentabilidade, com a reutilização dessa água na própria caldeira com temperatura de aproximadamente 70 a $80^{\circ} \mathrm{C}$. Assim, foi possível observar redução de custos devido ao menor consumo de água, uma vez que anteriormente era utilizada água da 
concessionária à temperatura ambiente e, menor gasto energético para aquecimento da água para vaporização, ou seja, menor utilização de matéria-prima de lenha (redução de 3,5 $\mathrm{m}^{3}$ de lenha para $2 \mathrm{~m}^{3}$ minimizando o corte de árvores). A média de gasto com água mensal seria de 87 m3 x 3,7088 = 320,684 - 30 $\%=96,21$ reais de economia no reaproveitamento da água da descarga de fundo e das válvulas de segurança. A energia que seria a lenha (3,5 m3-2,0 m3), economizou-se 1,5 m3 por dia após o reaproveitamento da água da descarga de fundo e das válvulas de segurança $(1,5 \mathrm{m3}$ × 30 dias $=45 \mathrm{m3} \times 55,00$ reais $=2.475,00$ reais de economia por mês).

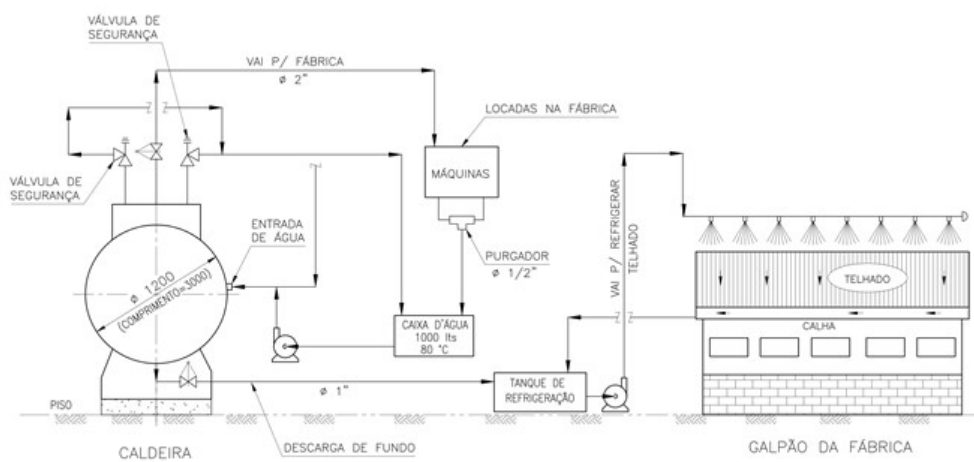

Figura 2: Fluxograma/projeto do sistema proposto de reúso da água de purgadores, válvulas de segurança e da descarga de fundo de caldeira em uma empresa do ramo de vestuário no município de Paraguaçu - MG.

\section{Análises de água da descarga de fundo}

A Figura 3 mostra as análises de água da descarga de fundo. Observou-se que os valores verificados no gráfico se apresentam abaixo dos parâmetros da normalidade devido à parada da produção. Consequentemente houve tratamento de água de forma parcial. Um possível tratamento é diminuir os sólidos dissolvidos na água, ficando nos padrões da norma da ABNT MB 969/97. Esse comportamento não foi verificado nos dias 07/06/2017, 20/12/2017 e 29/06/2018. Nesse sentido foi recomendada a aplicação do produto AQUA 3000 em $800 \mathrm{~mL}$ para cada 10 horas de trabalho e a efetuação rigorosa da descarga de fundo a cada 2 horas com duração de 10 segundos, equilibrando o pH e consequentemente as variáveis de alcalinidade. Após a aplicação dos produtos sempre é feito analise, comprovando a eficiência da aplicação.

$\mathrm{O} \mathrm{pH}$ bem como as alcalinidades total, de hidróxido e carbonatos mostraram-se reduzidas nos dias 20/06/17 e 29/06/17 e com relação inversa à alcalinidade bicarbonato. Cabe ressaltar que as variáveis pH e alcalinidade tem forte relação segundo Von Sperling (2005) e acima de 9,4 predominam alcalinidade de hidróxidos e carbonatos. Conforme observado, houve maior concentração em função do baixo pH.

Quanto ao $\mathrm{pH}$, foram observados valores abaixo do preconizado em três períodos (junho e dezembro de 2017 e junho de 2018), coincidindo com a época de baixa produção, podendo o mesmo ser associado a tal fato, ou ainda provavelmente ser devido ao dia específico de coleta em que os valores de substâncias químicas podem ter aumentado ou diminuído de acordo com o tratamento químico dado. Quando os valores se encontram abaixo do limite pode ocorrer corrosão em caldeiras, podendo levar à acidentes, perda de material e parada do equipamento para manutenção (GENTIL, 1996). 


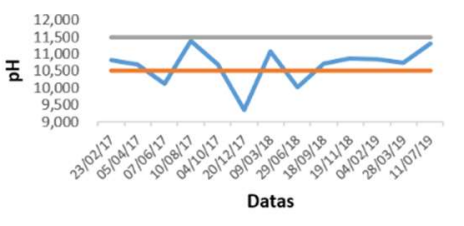

- $\mathrm{PH}$-PADRÄOMIN —PADRÃO MAX
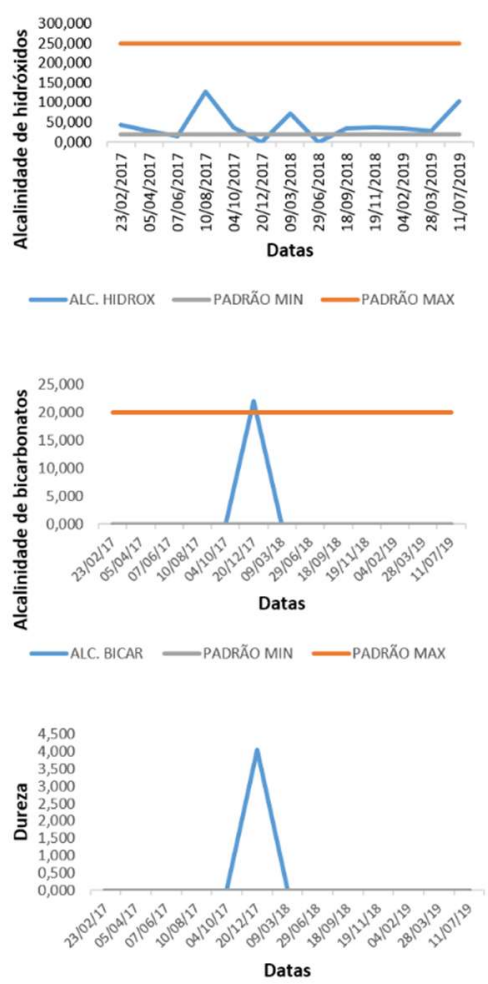

—DUREZA TOTAL —PADRÃO MIN —PADRÃo MAX
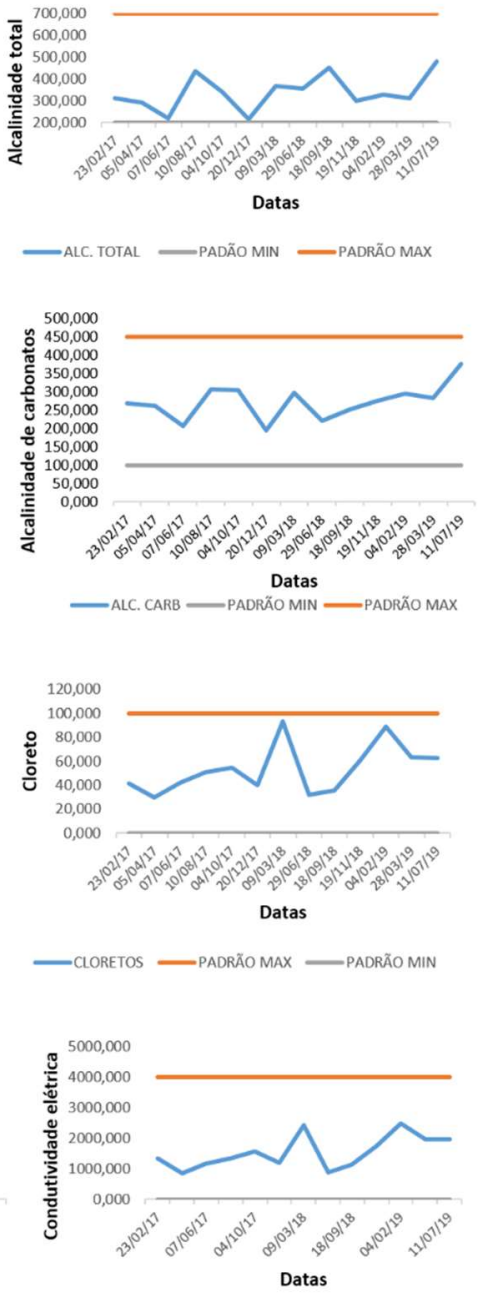

— CONDUTIV —PADRÄO MAX —PADRÃO MIN

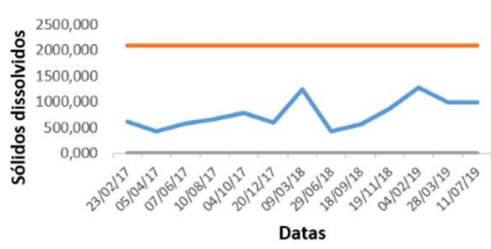

- SOL.T. DIS —PADRÄO MAX —PADRÄO MIN

Figura 3: Variáveis analisadas na água de descarga de fundo de caldeira durante o período e os limites estabelecidos pela Marchand Chimie. Unidades: $\mathrm{pH}$ (sem unidade); condutividade elétrica em $\mu \mathrm{S} . \mathrm{cm}^{-1}$ e demais variáveis em $\mathrm{mg} . \mathrm{L}^{-1}$

As concentrações de alcalinidade total variaram de 216 a $478 \mathrm{mg} \mathrm{L}^{-1}$ estando dentro dos limites recomendados, indicando maior capacidade do meio em resistir a mudanças do $\mathrm{pH}$. Entretanto, os valores de $\mathrm{pH}$ mesmo seguindo o preconizado, encontram-se abaixo do limite mínimo recomendado. As alcalinidades encontradas em todas as amostras foram predominantemente influenciadas por carbonatos e hidróxidos.

Quanto à alcalinidade bicarbonato verificou-se um pico na data de 20/06/2017 que, segundo General Eletric Company (2012), pode produzir espuma e arraste com vapor; fragilização do aço da caldeira e ainda produzir $\mathrm{CO} 2$ no vapor sendo consequentemente uma fonte de corrosão em linhas de condensado.

As maiores concentrações de cloreto foram nos períodos de 09/03/2018 e 04/02/2019, com concentrações de 93,3 e 88,7 $\mathrm{mg} \mathrm{L}^{-1}$, respectivamente; valores bem próximos ao limite estabelecido. De acordo com Andrade et al. (2008), os cloretos podem estar presentes na forma de sais de cálcio, ferro e 
magnésio. Se observadas altas concentrações, esses íons podem causar corrosão em tubulações e caldeiras, equipamentos de aço inoxidável, formar incrustações em pisos, paredes e equipamentos. Assim fica clara a importância do uso de água com baixo nível de cloretos, uma vez que o desequilíbrio dessa variável pode causar problemas com equipamentos, prejudicando o andamento do processo na indústria.

Em relação à dureza total, observou-se um pico somente no dia 20/12/2017, o que permite inferir, em associação com as demais variáveis, que é provável que algum colapso no sistema tenha acontecido na referida data. Segundo Figueiredo (2002), para a indústria este é um comportamento indesejável e deve ser tratado, uma vez que em temperaturas elevadas esses minerais acabam formando incrustações, se tornando um perigo para caldeiras e outros equipamentos. Esses minerais também causam problemas na parte da higienização, podendo reagir com sabões e detergentes, diminuindo sua eficiência. Já para Zarpelon et al. (2015), quanto maior a temperatura de operação de uma caldeira, menor é a tolerância aos depósitos, o que dificulta a troca de calor com consequentes danos e rompimentos. Os tubos de metal da caldeira, além da perda de resistência mecânica e deformações, em razão do superaquecimento deles, restringem a área do fluxo de escoamento na linha com possíveis obstruções nas válvulas, resultando em perdas e reposições caras.

Avaliando-se a condutividade elétrica e os sólidos dissolvidos totais observou-se que as variáveis estão dentro do limite estabelecido.

No geral, as análises permitiram constatar que a água de descarga de fundo pode ser reaproveitada no processo de resfriamento do telhado. Deve-se, portanto, atentar para os períodos de baixa produção. Quando as variáveis ultrapassarem os valores máximos e mínimos permitidos, deve-se realizar tratamentos adequados tais como abrandamento com adição de cal ou soda cáustica, troca catiônica, ou tratamento com adição de ácido, desmineralização, tratamento interno para caldeira, osmose reversa, dentre outros. Pode ser adotado qualquer um dos métodos, desde que seja eficiente e de menor custo. Por ser uma caldeira fogotubular e também por ser um tratamento mais econômico, recomenda-se o processo de tratamento interno para caldeiras.

\section{Análises de água das válvulas de segurança e água da descarga de fundo de caldeira}

A Tabela 3 apresenta as variáveis de análise de água de válvulas de segurança e purgadores e água da descarga de fundo da caldeira, bem como os valores de referência.

Tabela 3: Variáveis de análise de água de válvulas de segurança e purgadores e água do telhado e os valores de referência, no período avaliado.

\begin{tabular}{|c|c|c|c|c|c|c|c|}
\hline Parâmetros & & Unidade & $\begin{array}{l}\text { Válvulas de segurança } \\
\text { purgadores }\end{array}$ & $\mathrm{e}$ & $\begin{array}{l}\text { Valores } \\
\text { referência* }\end{array}$ & $\begin{array}{l}\text { Água do } \\
\text { telhado }\end{array}$ & $\begin{array}{ll}\begin{array}{l}\text { Valor } \\
\text { referência** }\end{array} & \text { de } \\
\end{array}$ \\
\hline $\mathrm{pH}$ & & - & 6,15 & & $11,0-12,0$ & 9,82 & $6,00-8,00$. \\
\hline Temperatura & & ${ }^{\circ} \mathrm{C}$ & 38,00 & & NA & 41,00 & NA \\
\hline $\begin{array}{l}\text { Alcalinidade } \\
\text { bicarbonatos }\end{array}$ & de & $m g \cdot L^{-1}$ & 1,20 & & NA & 2,50 & NA \\
\hline $\begin{array}{l}\text { Alcalinidade } \\
\text { carbonatos }\end{array}$ & de & $\mathrm{mg} \cdot \mathrm{L}^{-1}$ & 1,70 & & NA & 3,80 & NA \\
\hline $\begin{array}{l}\text { Alcalinidades } \\
\text { hidróxidos }\end{array}$ & de & $\mathrm{mg} \cdot \mathrm{L}^{-1}$ & 3,40 & & NA & 25,50 & NA \\
\hline Alcalinidade total & & $\mathrm{mg} \cdot \mathrm{L}^{-1}$ & 30,00 & & $150,0-600,0$ & 280,00 & NA \\
\hline
\end{tabular}




\begin{tabular}{llllll} 
Cloretos & $\mathrm{mg} \cdot \mathrm{L}^{-1}$ & 10,00 & $\mathrm{NA}$ & 33,00 & $\mathrm{NA}$ \\
Cloro residual livre & $\mathrm{mg} \cdot \mathrm{L}^{-1}$ & 0,103 & $\mathrm{NA}$ & 0,521 & $0,50-1,50$ \\
Condutividade elétrica & $\mu \mathrm{S} \cdot \mathrm{cm}^{-1}$ & 47,90 & $<3.000,0$ & $1.045,0$ & $\mathrm{NA}$ \\
Dureza total & $\mathrm{mg} \cdot \mathrm{L}^{-1}$ & 0,70 & $<50,00$ & $\mathrm{NA}$ \\
Ferro total & $\mathrm{mg} \cdot \mathrm{L}^{-1}$ & 0,033 & $<5,00$ & 0,007 & $\mathrm{NA}$ \\
Sólidos dissolvidos totais & $\mathrm{mg} \cdot \mathrm{L}^{-1}$ & 35,80 & $<1.500,0$ & 947,50 & $<200,00$ \\
\hline
\end{tabular}

* Especificações da Marchand Chimie

** Padrões para Classe 1 da Norma ABNT - NBR 13.969/97

NA- Não se aplica

Com relação às variáveis de válvula de segurança e purgadores, foi possível constatar que pH e alcalinidade total se encontram fora dos limites estabelecidos pelas especificações da Marchand Chimie. Assim, para a utilização dessa água no processo de vaporização da caldeira, recomenda-se tratamento por abrandamento com cal e/ou soda cáustica para posterior uso.

Em relação a água do telhado de acordo com os padrões para Classe 1 - Lavagem de carros e outros usos que requerem o contato direto do uso da água, com possível aspiração de aerossóis pelo operador incluindo chafarizes conforme a Norma ABNT - NBR 13.969/97, observou-se que o pH se encontra acima dos limites estabelecidos necessitando de correção e os sólidos dissolvidos. Um possível tratamento para a resolução da correção das variáveis que não atendem ao limite estabelecido seria observar o aumento da temperatura no telhado.

\section{Análises de conforto térmico}

A Tabela 4 apresenta as análises relacionadas ao conforto térmico na empresa.

Tabela 4: Temperaturas do ar dentro da empresa com sistema de refrigeração por meio da irrigação com água reutilizada de caldeiras sobre o telhado em uso.

\begin{tabular}{llll}
\hline \multirow{2}{*}{ Data } & Horário das medições & Em desuso & Em uso \\
\cline { 3 - 4 } & & Temperatura $\left({ }^{\circ} \mathrm{C}\right)$ & \\
\hline \multirow{2}{*}{$19 / 09 / 2019$} & $15: 00$ & 27,0 & 23,0 \\
& $15: 10$ & 27,0 & 23,9 \\
\hline & $15: 20$ & 27,5 & 23,7 \\
\hline
\end{tabular}

A data de realizações foi de acordo com a disponibilidade da empresa para que o projeto fosse aplicado (19/09/2019). Sendo que os meses de temperatura mais elevadas (novembro a março), são os meses mais propícios para as medições.

Observando-se a situação de uso e desuso do sistema de refrigeração por meio da irrigação de água sobre o telhado no ambiente de trabalho, nota-se que houve redução em valores médios de $3,7^{\circ} \mathrm{C}$. Ressaltase que a permanência das mesmas condições físicas do ambiente de trabalho e as condições climáticas de influência externa nos dias de avaliações possibilitaram a similaridade garantindo os registros das temperaturas.

As práticas de higiene relativa ao calor (conforto térmico por meio da amenização da temperatura em um ambiente) são particularmente importantes porque minimizam as condições de um indivíduo em sofrer um dano a saúde relacionado ao risco. Em se tratando de conforto térmico, pode-se concluir que o resultado é significativo, com valores de temperatura de $23,5^{\circ} \mathrm{C}$ quando o sistema de irrigação dos telhados 
está em operação. Esse comportamento colabora com a NR-17 que trata sobre ergonomia no trabalho, sendo que a mesma estipula índice de temperatura efetiva entre 20 e $23^{\circ} \mathrm{C}$.

\section{CONCLUSÕES}

A água de descarga de purga e descarga das válvulas de segurança de caldeiras que atinjam aproximadamente $70^{\circ} \mathrm{C}$ a $80^{\circ} \mathrm{C}$ pode ser reutilizada na própria caldeira com consequente economia de lenha e água, devendo-se, entretanto, proceder a um tratamento com adição de cal e/ou soda cáustica. A temperatura da água for abaixo de $70^{\circ} \mathrm{C}$ também pode ser usada, quanto mais quente, menos lenha gasta para aquecer a caldeira.

A água de descarga de fundo pode ser reaproveitada no processo de resfriamento do telhado. 0 reúso de água no telhado mostrou-se satisfatório com redução da temperatura em torno de $3,7^{\circ} \mathrm{C}$ dentro da indústria. No entanto, deve-se fazer tratamento para remoção de sólidos dissolvidos.

\section{REFERÊNCIAS}

ABNT. Associação Brasileira de Normas Técnicas. NBR 9898. Preservação e Técnicas de Amostragem de Efluentes Líquidos e Corpos Receptores - Procedimento. Rio de Janeiro: ABNT, 1987.

ABNT. Associação Brasileira de Normas Técnicas. NBR 13.969: Tanques sépticos Unidades de tratamento complementar e disposição final dos efluentes líquidos. Projeto, Construção e Operação. Rio de Janeiro: ABNT, 1997.

ANDRADE, N. J.; MACEDO, J. A. B.. Higienização na Indústria de Alimentos. São Paulo: Livraria Varela, 2008.

APHA; AWWA; WEF. American Public Health Association; American Water Works Association; World Economic Forum. Standard methods for the examination of water and wastewater. $21 \mathrm{ed}$. Washington: American Public Health Association, 2005.

BRASIL. Ministério do Trabalho e Emprego. NR 13: Caldeiras à vapor. Brasília: Ministério do Trabalho e Emprego, 1978.

BRASIL. Ministério de Minas e Energia. Balanço Energético
Nacional 2015: ano base 2014. Brasília: MME, 2015.

FIGUEIREDO, R. M.. Programa de redução de

patógenos: padrões e procedimentos operacionais de sanitização. São Paulo: Manole Técnicos, 2002.

GENTIL, V.. Corrosão. 3 ed. Rio de Janeiro: S.A., 1996.

ROTHBARTH, A.. Tratamento de água para caldeiras de alta pressão. Revista e Portal Meio Filtrante, v.42, 2010.

TROVATI, J.. Tratamento de água para geração de vapor: caldeiras. Snatural, 2014.

VON SPERLING, M.. Princípios do Tratamento Biológico de Águas Residuárias: introdução à qualidade das águas e ao tratamento de esgotos. 4 ed. 2014.

ZARPELON, W.; AZZOLINI, J. C.. Caldeiras de alta pressão: caracterização e avaliação da qualidade do tratamento das águas de abastecimento. Unoesc \& Ciência, v.6, n.2, p.141154, 2015.

A CBPC - Companhia Brasileira de Produção Científica (CNPJ: 11.221.422/0001-03) detém os direitos materiais desta publicação. Os direitos referem-se à publicação do trabalho em qualquer parte do mundo, incluindo os direitos às renovações, expansões e disseminações da contribuição, bem como outros direitos subsidiários. Todos os trabalhos publicados eletronicamente poderão posteriormente ser publicados em coletâneas impressas sob coordenação da Sustenere Publishing, da Companhia Brasileira de Produção Científica e seus parceiros autorizados. Os (as) autores (as) preservam os direitos autorais, mas não têm permissão para a publicação da contribuição em outro meio, impresso ou digital, em português ou em tradução. 